\title{
Dermatological conditions seen in renal transplant recipients in a Singapore tertiary hospital
}

\author{
Choon Chiat $\mathrm{Oh}^{1}$, MBBS, MRCP, Haur Yueh Lee ${ }^{1}$, MBBS, MRCP, Bien Keem Tan ${ }^{2}$, MBBS, FRCS, \\ Pryseley Nkouibert $\underline{A s s a m}^{3}$, MSc, PhD, Terence Yi Shern $\underline{K e}^{4}$, MBBS, FRCP, Shiu Ming $\underline{\text { ang }}^{1}$, MBBS, FRCP
}

INTRODUCTION Lifelong immunosuppression after renal transplant exerts effects on the recipients' skin, including skin infections, skin cancers and drug-induced skin disorders. Our study aimed to determine the epidemiology of skin conditions among renal transplant recipients in the largest tertiary hospital in Singapore.

METHODS We reviewed the medical records of kidney transplant recipients at Singapore General Hospital, Singapore, between 1 January 2003 and 31 December 2013. Among these patients, the clinical data of patients who sought skin consultations with either dermatologists or plastic surgeons within the hospital was captured.

RESULTS A total of 178 patients were included in our study. There were 88 (45.6\%) skin infections, 23 (11.9\%) druginduced skin conditions, 9 (4.7\%) skin cancers and $73(37.8 \%)$ other skin conditions. Skin infection was the predominant reason for consultation, with viral warts $(15 \%, n=29)$ being the most common. Of the nine cases in our cohort with skin cancer, there were three cases of basal cell carcinoma, three cases of Bowen's disease, two cases of extramammary Paget's disease and one case of squamous cell carcinoma. Drug-induced skin conditions, mainly attributable to longterm steroids and cyclosporin use, were represented by acne $(9.3 \%, n=18)$ and sebaceous hyperplasia $(2.6 \%, n=5)$. CONCLUSION Our study demonstrated the spectrum of skin conditions that can be expected after renal transplantation. We wish to highlight the importance of careful dermatological screening and long-term follow-up for these patients, in order to reduce post-transplant skin complications.

Keywords: human papilloma virus, renal transplant, skin cancers, skin infections

\section{INTRODUCTION}

In Singapore, the number of kidney transplant recipients is on the rise every year as a result of rapid surgical and medical advancements. Renal transplantation provides a better standard of care for the increasing number of patients with end-stage renal disease, reducing long-term morbidity and mortality. However, lifelong immunosuppressive treatment after renal transplant exerts effects on a recipient's skin. Skin conditions range widely from skin cancers and skin infections to drug-induced skin disorders such as acne and sebaceous gland hyperplasia.

In solid-organ transplant centres across Europe and America, skin cancer is the most common skin condition to arise after organ transplantation, and the rates of squamous cell carcinoma (SCC), basal cell carcinoma (BCC) and Kaposi sarcoma are known to be greatly increased in organ transplant recipients. ${ }^{(1,2)}$ However, there is a paucity of data from Asian countries. Earlier publications reported that skin cancers arise at a much lower frequency in organ transplant recipients. ${ }^{(3-6)}$ Our study aimed to determine the epidemiology of skin conditions among renal transplant recipients in the largest tertiary hospital in Singapore.

\section{METHODS}

We reviewed the medical records of 611 kidney transplant recipients at Singapore General Hospital, Singapore, between 1 January 2003 and 31 December 2013. Among these patients, the clinical data of patients who sought skin consultations with either dermatologists or plastic surgeons within the hospital was captured. The age, gender, ethnicity, type of donor organ transplant, time after transplantation and regimen of immunosuppressive therapy used were recorded. History of skin lesions and examination findings were obtained. Specific tests were performed for appropriate cases, including skin and nail scraping for microscopy and culture for suspected superficial fungal infections. Gram staining for suspected pyogenic infections and skin biopsies were performed for appropriate cases (e.g. skin cancers). Immunosuppression protocol during the study period was risk-stratified according to immunological risks and patientrelated comorbidities.

Antibody induction therapies were used for the majority of patients, and these were usually interleukin-2 receptor antagonists (e.g. basiliximab). Thymoglobulin and rituximab were reserved for patients at high immunological risk of rejection, such as in cases of positive crossmatch or ABO-incompatible kidney transplantation. Maintenance agents included calcineurin inhibitors such as cyclosporin $5 \mathrm{mg} / \mathrm{kg} /$ day or tacrolimus $0.10-0.15 \mathrm{mg} / \mathrm{kg} /$ day, and antiproliferative agents such as azathioprine $1 \mathrm{mg} / \mathrm{kg} /$ day or mycophenolate mofetil 20-24 mg/kg/day. In selected cases, alternative antiproliferative agents such as mTOR inhibitors (sirolimus $2 \mathrm{mg} /$ day or everolimus 1.5-3.0 mg/kg/day) were used instead of azathioprine or mycophenonate mofetil. When acute rejection occurred, three days of intravenous methylprednisolone $500 \mathrm{mg}$ /day was given, while thymoglobulin was reserved

${ }^{1}$ Department of Dermatology, ${ }^{2}$ Department of Plastic, Reconstructive and Aesthetic Surgery, Singapore General Hospital, ${ }^{3}$ Centre for Quantitative Medicine, Duke-NUS Medical School, ${ }^{4}$ Department of Renal Medicine, Singapore General Hospital, Singapore

Correspondence: Dr Choon Chiat Oh, Consultant, Department of Dermatology, Singapore General Hospital, Academia, 20 College Road, Singapore 169856. oh.choon.chiat@singhealth.com.sg 
Table I. Demographics of renal transplant recipients.

\begin{tabular}{|ll|}
\hline Characteristic & No. (\%) \\
\hline Gender & \\
\hline Male & $108(60.7)$ \\
\hline Female & $70(39.3)$ \\
\hline Ethnicity & $141(79.2)$ \\
\hline Chinese & $18(10.1)$ \\
\hline Malay & $12(6.7)$ \\
\hline Indian & $7(3.9)$ \\
\hline Others & \\
\hline Age (yr) & $38(21.3)$ \\
\hline $20-40$ & $98(55.1)$ \\
\hline $41-60$ & $42(23.6)$ \\
\hline $61-80$ & \\
\hline Type of donor* & $44(24.9)$ \\
\hline Living & $133(75.1)$ \\
\hline Deceased
\end{tabular}

*Data available for 177 patients.

for corticosteroid-resistant T-cell-mediated rejection or severe vascular rejection. Antibody-mediated rejection was treated with rituximab, plasma exchange and intravenous immunoglobulin.

All frequency data was presented as numbers and percentages. The study was reviewed and approved by the Institutional Review Board at Singapore General Hospital.

\section{RESULTS}

A total of 178 patients were included in our study cohort. The general characteristics of these patients are summarised in Table I. Among these patients, 108 were male and 70 were female. Their age range was $20-80$ years with a mean age of $51.1 \pm 12.0$ years. The majority of the participants were Chinese $(79.2 \%, \mathrm{n}=141)$.

These patients had received kidneys from either living or deceased donors, with available data indicating 44 (24.9\%) living donors and 133 (75.1\%) deceased donors. The mean time interval from transplantation to their first skin consultation was 4.3 years (range 1 month to 27 years). Table II shows the various skin conditions that were diagnosed. There were 88 cases $(45.6 \%)$ of skin infections, 23 (11.9\%) drug-induced skin conditions, 9 (4.7\%) skin cancers and 73 (37.8\%) other skin conditions. Skin infection was the predominant reason for consultation, with viral warts $(15 \%, n=29)$ being the most common infection. Data on the cases of viral warts is summarised in Table III (tinea/onychomychosis/ pityriasis versicolor).

Viral warts have a predilection for sun-exposed skin, including the head and neck region, and the upper trunk. They can be generalised, covering almost the entire body. In our study, most of the warts developed within the first five years after the renal transplant. As shown in Table II, out of 193 skin conditions, other commonly encountered skin infections included fungal infections of the skin $(9.3 \%, \mathrm{n}=18)$, cutaneous bacterial infections $(7.3 \%, \mathrm{n}=14)$ herpes zoster infections $(6.7 \%, \mathrm{n}=13)$ and onychomycosis $(5.2 \%, \mathrm{n}=10)$. Similar to viral warts, the majority of these infections developed within the first five years after the renal transplant (Table IV).
Table II. Epidemiology of skin conditions $(n=193)$.

\begin{tabular}{|c|c|}
\hline Parameter & No. (\%) \\
\hline Infectious disease & $88(45.6)$ \\
\hline Viral warts & 29 \\
\hline $\begin{array}{l}\text { Cutaneous fungal infection } \\
\text { (dermatophyte/candida/pityriasis versicolor) }\end{array}$ & 18 \\
\hline Herpes zoster & 13 \\
\hline Cutaneous bacterial infection (cellulitis/abscess) & 14 \\
\hline Onychomycosis & 10 \\
\hline Molluscum contagiosum & 2 \\
\hline $\begin{array}{l}\text { Cutaneous tuberculosis/non-tuberculous } \\
\text { mycobacterium }\end{array}$ & 2 \\
\hline Herpes simplex & 1 \\
\hline Skin cancer & $9(4.7)$ \\
\hline Basal cell carcinoma & 3 \\
\hline Bowen's disease & 3 \\
\hline Extramammary Paget's disease & 2 \\
\hline Squamous cell carcinoma & 1 \\
\hline Drug-induced condition & $23(11.9)$ \\
\hline Acne & 18 \\
\hline Sebaceous hyperplasia & 5 \\
\hline Others & $73(37.8)$ \\
\hline Eczema & 24 \\
\hline Hair loss & 7 \\
\hline Seborrhoeic keratosis & 6 \\
\hline Epidermal cyst & 5 \\
\hline Benign naevus/lentigo & 5 \\
\hline Traumatic wound (e.g. laceration, burn) & 5 \\
\hline Drug exanthem & 4 \\
\hline Psoriasis & 3 \\
\hline Vasculitis & 3 \\
\hline Lipoma & 2 \\
\hline Panniculitis & 2 \\
\hline Nephrogenic systemic fibrosis & 1 \\
\hline Perforating dermatosis & 1 \\
\hline Steatocystoma & 1 \\
\hline Hidradenitis suppurativa & 1 \\
\hline Contact dermatitis & 1 \\
\hline Keloid & 1 \\
\hline Pigmented purpuric dermatosis & 1 \\
\hline
\end{tabular}

Some patients had more than one skin condition, and data was calculated based on total no. of skin conditions.

There were $2(1.0 \%)$ cases of molluscum contagiosum infection, $2(1.0 \%)$ cases of cutaneous tuberculosis/nontuberculous mycobacterium infection and $1(0.5 \%)$ case of herpes simplex infection (Table II). The nine cases of skin cancer in our cohort are shown in Table $\mathrm{V}$, and consisted of BCC $(n=3)$, Bowen's disease $(n=3)$, extramammary Paget's disease $(n=2)$ and SCC $(n=1)$. All these patients underwent surgical excision. In contrast to skin infections, half of these cases of skin cancers developed after the first five years following the transplant.

The drug-induced skin conditions in our study consisted of acne $(9.3 \%, \mathrm{n}=18)$ and sebaceous hyperplasia $(2.6 \%, \mathrm{n}=5)$, and 
were mainly attributable to long-term steroids and cyclosporin use. Among the skin conditions classified as others, eczema was reported in $24(12.4 \%)$ cases, hair loss in 7 (3.6\%) cases and seborrhoeic keratosis in $6(3.1 \%)$ cases. Other less commonly reported cases were epidermal cysts $(2.6 \%, n=5)$, benign naevi or lentigenes $(2.6 \%, \mathrm{n}=5)$, traumatic wounds $(2.6 \%, \mathrm{n}=5)$ and drug exantham $(2.1 \%, \mathrm{n}=4)$.

\section{DISCUSSION}

In our study, skin infections were the most commonly encountered skin condition, with human papillomavirus (HPV) infection having the highest incidence, as represented by viral warts cases. $\mathrm{HPV}$ infection is one of the most frequent infections in transplant recipients. The prevalence of warts increases with the length of graft survival, and up to $50 \%$ of renal transplant recipients with graft survival $>5$ years have warts. ${ }^{(7)} \mathrm{HPV}$ infection in transplant recipients is also important because of its link to the development of skin cancers, in particular SCC. ${ }^{(7-10)}$ The commonly prescribed therapies include physical destruction (cryotherapy, laser or curettage), topical medications (salicylic acid or imiquimod) and systemic drugs (oral retinoids or switching to an mTOR inhibitor). In practice, multiple types of treatment are used in combination. ${ }^{(11-13)}$

Cutaneous warts in immunosuppressed patients are difficult to treat and were reported to have a significant impact on their quality of life, resulting in a form of physical stigma for the patients. A study by Zachariae et al reported that transplant patients with viral warts had an increased Dermatology Life Quality Index score (i.e. the skin disease had a greater negative impact) compared to those without viral warts. ${ }^{(14)}$ The role of HPV vaccination prior to transplant has also been explored in some studies. ${ }^{(15,16)}$ However, their results are presently inconclusive and further studies will be needed to determine an optimal HPV vaccine type and schedule for this population. It is important to note that ultraviolet radiation from the sun is immunosuppressive, which explains the predilection of viral warts for sun-exposed sites in the transplant recipients. Ultraviolet radiation from the sun is the most important cause of skin cancers, exerting a direct mutagenic effect on the DNA of keratinocyte stem cells and an indirect tumour-promoting effect. Hence, sun protection as well as daily application of sunscreen must be a standard

Table III. Duration from post renal transplant to diagnosis and location of viral warts.

\begin{tabular}{|ll|}
\hline Parameter & No. \\
\hline Time after renal transplant (yr) & \\
\hline $0-5$ & 21 \\
\hline $6-10$ & 5 \\
\hline$>10$ & 0 \\
\hline Location of warts & \\
\hline Generalised & 9 \\
\hline Head and neck & 8 \\
\hline Upper limbs & 6 \\
\hline Upper trunk & 1 \\
\hline Lower limbs & 3 \\
\hline Lower trunk & 0 \\
\hline Genitals & 2 \\
\hline
\end{tabular}

3 patients had warts before the transplant.

Table IV. Other types of common skin infections and their duration from post renal transplant to diagnosis.

\begin{tabular}{|lll|}
\hline Type of infection & Time after renal transplant (yr) & No. \\
\hline Fungal infection* (tinea/onychomycosis/pityriasis versicolor) & $0-5$ & 22 \\
\cline { 2 - 3 } & $6-10$ & 2 \\
\hline Herpes zoster $^{\dagger}$ & $>10$ & 0 \\
\hline Cellulitis/abscess $^{\ddagger}$ & $0-5$ & 10 \\
\hline & -10 & 1 \\
\hline
\end{tabular}

Infection developed in *4 patients, +1 patient and $\neq 1$ patient before transplant.

Table V. Duration from post renal transplant to diagnosis and tumour location of skin cancer cases.

\begin{tabular}{|llll|}
\hline Cancer type & Patient no. & Time after renal transplant (yr) & Location \\
\hline Squamous cell carcinoma & 1 & 5 & Arm \\
\hline Bowen's disease & 2 & 10 & Face \\
\cline { 2 - 4 } & 3 & 7 & Forearm \\
\hline Basal cell carcinoma & 4 & 6 & Forearm \\
\hline Extramammary Paget's disease & 5 & 10 & Face \\
\hline
\end{tabular}


recommendation for immunosuppressed persons, to prevent viral warts and subsequently reduce the risk of skin cancers. ${ }^{(15,16)}$ This is especially important due to Singapore's location at a low latitude near the equator. ${ }^{(17)}$

Studies of transplantation cohorts in the United States and western Europe reported an incidence of cutaneous SCC of $10 \%-27 \%$ at ten years after transplant and $40 \%-60 \%$ at 20 years after transplant, representing a 65-fold increase in SCCs and a ten-fold increase in BCCs. ${ }^{(18-20)}$ In contrast, the incidence of post-transplantation skin cancers is low in Asian recipients. Previous studies in Asia, especially those in Korea, Japan, India and Taiwan, reported that the proportion of transplant recipients with skin cancer was less than $2.1 \%$ of the total recipients. ${ }^{(21-23)} \mathrm{A}$ Singapore study by Sng et $\mathrm{al}^{(24)}$ reported that overall skin cancer incidence rates were 8.4 out of 100,000 in 1998-2002 and 7.4 out of 100,000 in 2003-2006. These incidence rates are much lower than those of Western countries. ${ }^{(24)}$ Similarly, skin cancers were relatively uncommon in our study at nine out of 611 renal transplant recipients, representing only $1.5 \%$ of the cohort. However, compared to the baseline incidence of skin cancers in Singapore, this represents a significantly increased risk. Despite the low rate of skin cancers in our study, it was imperative to maintain a high level of vigilance in our transplant cohort. Multiple verrucous skin changes are a clinical warning sign of a markedly increased risk for SCC. Immunosuppression disproportionately increases the incidence of SCCs: they grow more rapidly, are more likely to metastasise and tend to infiltrate blood vessel walls and invade perineurial sheaths. ${ }^{(25,26)}$

Drug-induced skin conditions in our study mainly included acneiform eruptions and sebaceous gland hyperplasia. These conditions, although harmless, can have an impact on patients' quality of life. Acne and folliculitis were generally related to steroid-based immunosuppressive regimens. Sebaceous gland hyperplasia was related to cyclosporin use. Other well-described cyclosporin-related skin disorders reported in the literature include hypertrichosis and gingival hyperplasia. ${ }^{(27)}$

An earlier study by our colleagues in this hospital showed the spectrum of dermatological cases in patients admitted to our hospital. Of the referrals made for dermatology consultations, eczema/dermatitis (33.1\%) and cutaneous infections $(23.4 \%)$ accounted for over half of the dermatological consultations, followed by cutaneous adverse drug reactions (12.3\%). (28) Our study demonstrates the difference between the spectrum of skin conditions encountered by the general population and those in the transplant population. We also observed that among the transplant population, skin infections develop early after the transplant, and skin cancers develop later. This finding requires validation through a larger prospective study.

Our study had several limitations. We could not exclude the possibility that our patients had skin diseases diagnosed at other clinics outside our institution. Additionally, we could not check for correlations between the nature of the immunosuppression and the skin diseases, as different drug regimes were used for our patients, with changes to the regimes and dosing over time. During the period of the study, most patients were referred on an ad- hoc basis and there was no routine pre- and post-transplant skin screening; as a result, skin conditions could have been missed. Lastly, this was a single-centre study and we may not be able to generalise the findings to other institutions.

Long-term management of transplant recipients is an interdisciplinary challenge, particularly with respect to the prevention and treatment of infectious diseases and cancer. There are also challenges in the choice of long-term immunosuppressants and drug interactions. Patients should also be educated about how to protect themselves from sunlight and simple self-examination methods. A protocol for pre- and post-transplant skin surveillance will assist in earlier detection of skin lesions, which translates to better treatment outcomes.

In conclusion, our study demonstrated the spectrum of skin conditions that can be expected after renal transplantation. It also highlights the importance of careful dermatological screening and long-term follow up for these patients, in order to reduce post-transplant skin complications. ${ }^{(29-32)}$

\section{ACKNOWLEDGEMENTS}

We would like to thank Ms Ma Yunlin, Ms Faith Lim Jia Min and Ms Tian Natasha Adam for their assistance in data collection.

\section{REFERENCES}

1. Berg D, Otley CC. Skin cancer in organ transplant recipients: epidemiology, pathogenesis, and management. J Am Acad Dermatol 2002; 47:1-17; quiz 18-20.

2. Euvrard S, Kanitakis J, Claudy A. Skin cancers after organ transplantation. N Engl J Med 2003; 348:1681-91

3. Park $\mathrm{GH}$, Chang $\mathrm{SE}$, Won $\mathrm{CH}$, et al. Incidence of primary skin cancer after organ transplantation: an 18-year single-center experience in Korea. J Am Acad Dermatol 2014; 70:465-72.

4. Chen QP, Aw DC. Epidemiology of skin diseases in renal transplant recipients in a tertiary hospital. Ann Acad Med Singapore 2010; 39:904-5.

5. Alper S, Kilinc I, Duman S, et al. Skin diseases in Turkish renal transplant recipients. Int J Dermatol 2005; 44:939-41.

6. George L, John GT, Jacob CK, et al. Skin lesions in renal transplant recipients: a single center analysis. Indian J Dermatol Venereol Leprol 2009; 75:255-61.

7. Tan $\mathrm{HH}$, Goh CL. Viral infections affecting the skin in organ transplant recipients: epidemiology and current management strategies. Am J Clin Dermatol 2006; 7:13-29.

8. Bouwes Bavinck JN, Berkhout RJ. HPV infections and immunosuppression. Clin Dermatol 1997; 15:427-37

9. Rudlinger R, Smith IW, Bunney MH, Hunter JA. Human papillomavirus infections in a group of renal transplant recipients. Br J Dermatol 1986; 115:681-92.

10. Bouwes Bavinck JN, Feltkamp M, Struijk L, ter Schegget J. Human papillomavirus infection and skin cancer risk in organ transplant recipients. J Invest Dermatol Symp Proc 2001; 6:207-11

11. Wolf IH. [Skin infections after transplantation]. Hautarzt 2010; 61:230-3. German.

12. Krüger-Corcoran D, Stockfleth E, Jürgensen JS, et al. [Human papillomavirusassociated warts in organ transplant recipients. Incidence, risk factors, management]. Hautarzt 2010; 61:220-9. German.

13. Boyle J, MacKie RM, Briggs JD, Junor BJ, Aitchison TC. Cancer, warts, and sunshine in renal transplant patients. A case-control study. Lancet 1984; 1:702-5.

14. Zachariae C, Sand C, Hansen JM, et al. Warts in a cohort of Danish kidney transplanted patients: impact on quality of life. Acta Derm Venereol 2012; 92:615-8.

15. Kumar D, Unger ER, Panicker G, et al. Immunogenicity of quadrivalent human papillomavirus vaccine in organ transplant recipients. Am J Transplant 2013; 13:2411-7.

16. Gomez-Lobo V, Whyte T, Kaufman S, Torres C, Moudgil A. Immunogenicity of a prophylactic quadrivalent human papillomavirus L1 virus-like particle vaccine in male and female adolescent transplant recipients. Pediatr Transplant 2014; 18:310-5.

17. Jensen P, Hansen S, Møller B, et al. Skin cancer in kidney and heart transplant recipients and different long-term immunosuppressive therapy regimens. J Am Acad Dermatol 1999; 40(2 Pt 1):177-86.

18. Hartevelt MM, Bavinck JN, Kootte AM, Vermeer BJ, Vandenbroucke JP. 
Incidence of skin cancer after renal transplantation in the Netherlands. Transplantation 1990; 49:506-9.

19. Bouwes Bavinck JN, Hardie DR, Green A, et al. The risk of skin cancer in renal transplant recipients in Queensland, Australia. A follow-up study. Transplantation 1996; 61:715-21.

20. Hoshida $Y$, Tsukuma $H$, Yasunaga $Y$, et al. Cancer risk after renal transplantation in Japan. Int J Cancer 1997; 71:517-20.

21. Kim HJ, Lee TW, Ihm CG, Kim MJ. Prevalence of cancers in Korean recipients of renal transplants. Nephrology 2002; 7:198-204.

22. Baghel N, Awasthi S, Kumar SS. Cutaneous manifestations in renal transplant recipients. Int J Res Med Sci 2017; 5:1823-8

23. Sng J, Koh D, Siong WC, Choo TB. Skin cancer trends among Asians living in Singapore from 1968 to 2006. J Am Acad Dermatol 2009; 61:426-32.

24. Joly P, Bastuji-Garin S, Frances C, et al. Squamous cell carcinomas are associated with verrucokeratotic cutaneous lesions but not with common warts in organtransplant patients. A case-control study. Transplantation 2010; 89:1224-30.

25. Mudigonda T, Levender MM, O'Neill JL, et al. Incidence, risk factors, and preventative management of skin cancers in organ transplant recipients: a review of single- and multicenter retrospective studies from 2006 to 2010. Dermatol
Surg 2013; 39:345-64.

26. Kripke ML. Ultraviolet radiation and immunology: something new under the sun--presidential address. Cancer Res 1994; 54:6102-5.

27. Ulrich $C$, Hackethal $M$, Meyer $T$, et al. Skin infections in organ transplant recipients. J Dtsch Dermatol Ges 2008; 6:98-105.

28. Tay LK, Lee HY, Thirumoorthy T, Pang SM. Dermatology referrals in an East Asian tertiary hospital: a need for inpatient medical dermatology. Clin Exp Dermatol 2011; 36:129-34.

29. Christenson LJ, Geusau A, Ferrandiz C, et al. Specialty clinics for the dermatologic care of solid-organ transplant recipients. Dermatol Surg 2004; 30:598-603.

30. Otley CC, Hirose R, Salasche SJ. Skin cancer as a contraindication to organ transplantation. Am J Transplant 2005; 5:2079-84.

31. Zwald FO, Brown M. Skin cancer in solid organ transplant recipients: advances in therapy and management, part I. Epidemiology of skin cancer in solid organ transplant recipients. J Am Acad Dermatol 2011; 65:253-61; quiz 262.

32. Kasiske BL, Vazquez MA, Harmon WE, et al. Recommendations for the outpatient surveillance of renal transplant recipients. American Society of Transplantation. J Am Soc Nephrol 2000; 11 Suppl 15:S1-86. 